by segregation to it of solute atoms, migration will be hindered if the rate of diffusion of the solute atoms is low, just as with an 'atmosphere' around a dislocation.

Metallurgy Division,

National Physical Laboratory,

Teddingt on, Middlesex. May 18.

${ }^{1}$ Wyon, G., and Crussard, C., Rev. Met., 48, 121 (1951). Chang, H. C., and Grant, N. J., J. Metals, 4, (6) (1952).

2 Shockley, W., and Read, W. T., Phys. Rev., 75, 692 (1949).

'Mott, N. F., Proc. Phys. Soc., 60, 391 (1948).

\section{Score Resistance of Bearing Metals}

SCORE resistance is the property of a bearing that enables it to resist welding to its journal. Although it is a property of the greatest technical importance, knowledge of score resistance has for many years been largely empirical, and efforts to relate score resistance to other more readily definable properties have met with only limited success.

In studying the performance of a large number of bearing metals, we have found that the good bearing metals are those which at their melting points have extremely limited solid solubilities in iron. Thus, lead, tin, indium, thallium and cadmium have excellent score resistance and negligible solubility in iron. Copper, gold, platinum and nickel, on the other hand, have poor score resistance and large solubility in iron. Silver, zine and aluminium are intermediate as regards both score resistance and solubility in iron. The more dissimilar two metals are, the greater will be their score resistance when rubbed together. Specifically, the metals should be dissimilar with regard to, first, crystal binding forces and, secondly, atomic sizes. The former factor is most readily described in terms of the periodic classification of elements, as was pointed out by Underwood'. 'Thus, the main journal metals (iron, nickel, chromium, manganese, vanadium and molybdenum) are all transition metals with strongly metallic binding. These, as well as metals (such as copper and gold) which immediately follow transition groups in the periodic classification, have poor score resistance when used as bearing metals in conjunction with steel journals. The $B$-subgroup metals (such as lead, tin, indium, cadmium and thallium), which have less strongly metallic binding, have been found to have excellent score resistance when run against transition metal journals. Exceptional cases are silver and zinc. Silver is a metal which occurs immediately after a transition group but which has unfavourable atomic size for alloying with iron (as defined by HumeRothery ${ }^{2}$ ) and technically acceptable score resistance when run against steel. Zine is two atomic numbers removed from a transition group but has a favourable atomic size and is an undesirable constituent of bearing metals.

The essentially non-metallic binding of intermetallic compounds indicates that such materials should have good score resistance, regardless of the score resistance of their constituents, and this has been borne out by our experiments.

The above factors provide an explanation for the anti-score characteristics conferred upon metal surfaces by films of compounds such as oxides, chlorides, sulphides, selenides and the like.
A more complete accour of these and other aspects of score resistance will be published elsewhere.

\section{ARVID E. ROACH}

Carl L. Gooczeit

Paul A. Totta

Mechanical Development Department,

Research Laboratories Division,

General Motors Corporation, Detroit, Michigan.

$$
\text { Jan. } 8 .
$$

${ }^{1}$ Underwood, A. F., Symp. on Sleeve Bearing Materials, 28th National Metal Congress, Atlantic City, N.J. (1946).

'Hume-Rothery, W., "The Structure of Metals and Alloys"' (Institute of Metals, Jondon, $195(i)$.

\section{Hydrolysis of Organic Nitrites}

IN continuation of investigations into the mechanisms of reactions of organic esters ${ }^{1}$, a study has been made of the hydrolysis of some simple organic nitrites. It was known $^{2}$ that the acid-catalysed hydrolysis of these esters is very rapid at room temperature, while the rate of reaction in alkaline media is comparatively slow.

Acid catalysis. The hydrolysis of $n$-propyl, tert.-butyl and benzhydryl nitrites has been studied at $0^{\circ} \mathrm{C}$. in 72.5 per cent dioxan-water (by weight) as solvent in the presence of small concentrations of mineral acids. Kinetics observed were of the first order with respect to the nitrite concentration, and with perchloric acid as the catalyst the first-order constants are directly proportional to the acid concentration over the range $0.001-0.007 M$, wherein the reaction proceeds at a convenient speed. For a fixed hydrogen ion concentration, and at constant ionic strength, a further marked catalysis was observed on addition of chloride and bromide ions, the increase in rate being proportional to the halide concentration up to $0.012 M$. The results may be interpreted as follows :

$$
\begin{aligned}
& R \mathrm{ONO}+\mathrm{H}^{+} \stackrel{\text { fast }}{\longrightarrow}(R \mathrm{ONOH})^{+} \\
& (R \mathrm{ONOH})^{+}+\mathrm{H}_{2} \mathrm{O} \stackrel{\text { slow }}{\longrightarrow} R \mathrm{OH}+\left(\mathrm{H}_{2} \mathrm{ONO}\right)^{+} \\
& (R \mathrm{ONOH})^{+}+\mathrm{X}^{-\stackrel{\text { slow }}{\longrightarrow}} R \mathrm{OH}+\mathrm{NOX}(X=\mathrm{Cl}, \mathrm{Br}) .
\end{aligned}
$$

Omitting the concentration of water, since this is

\begin{tabular}{|c|c|c|}
\hline & $\left.\underset{\left(\mathrm{sec}^{-1} \mathrm{gm} .\right.}{k_{2}} \mathrm{~mol}^{-1} 1.\right)$ & $\begin{array}{c}k_{8}(\text { for } X=\mathrm{Br}) \\
\left(\mathrm{sec}^{-1} \mathrm{gm}, \mathrm{mol} .^{-2} \mathrm{l.}^{2}\right)\end{array}$ \\
\hline $\begin{array}{l}n \text {-Propyl nitrite } \\
\text { tert.-Butyl nitrite } \\
\text { Benzhydryl nitrite }\end{array}$ & $\begin{array}{l}0 \cdot 218 \\
0 \cdot 526 \\
0 \cdot 19\end{array}$ & $\begin{array}{r}26 \cdot 8 \\
8 \cdot 9 \\
27\end{array}$ \\
\hline
\end{tabular}
in large excess, the expression for the rate becomes : $\frac{-\mathrm{d}(R \mathrm{ONO})}{\mathrm{d} t}=k_{2}\left(\mathrm{H}^{+}\right)(R \mathrm{ONO})+k_{3}\left(\mathrm{H}^{+}\right)(R \mathrm{ONO})\left(\mathrm{X}^{-}\right)$.

Values of $k_{2}$ and $k_{3}$ are :

Alkaline catalysis. The hydrolysis of $n$-propyl and tert.-butyl nitrites by sodium hydroxide in 60 per cent dioxan-water has been studied over the temperature range $25-55^{\circ} \mathrm{C}$. Good second-order kinetics were observed, and the rate constants are found to be in accordance with the usual relationship :

$$
\log _{10} k_{2}=\log _{10} A-\frac{E}{2 \cdot 303 R T} .
$$

